\title{
Cuestiones procesales de los privilegios marítimos
}

\author{
Procedural issues of maritime liens
}

\author{
MARÍA NIEVES JIMÉNEZ LÓPEZ \\ Profesora Contratada Doctora de Derecho Procesal \\ Universidad de Málaga (España) \\ mnievesj1@uma.es
}

https://orcid.org/0000-0001-5596-2133

\begin{abstract}
Resumen: Tiene por objeto este trabajo, analizar la tutela procesal que nuestro ordenamiento concede a los denominados privilegios marítimos, como créditos de especial naturaleza que existen, tanto a nivel nacional como internacional, desde tiempos remotos, como mecanismo para facilitar la financiación del comercio marítimo, pues éstos otorgan a sus titulares una serie de privilegios especiales para la satisfacción del crédito. Para ello, comenzaremos por determinar los aspectos más relevantes de su configuración legal, para así poder abordar, posteriormente, la tutela procesal que estos privilegios reciben, centrándonos, no sólo en analizar las distintas acciones a través de las cuales, los titulares de estos créditos pueden ejercitar sus derechos, si no también, como pueden éstos hacer valer el privilegio de crédito frente a otros acreedores que hubiesen iniciado un proceso de ejecución en el que se hubiese embargado o se pudiese embargar el buque que sirve de garantía a los créditos con privilegio marítimo, estableciendo además, en qué orden deben ser satisfechos.

Profundizaremos, además, determinando cuáles son los créditos que tienen la consideración de créditos marítimos privilegiados, los distintos tipos que existen y analizando las especialidades procesales que se contienen tanto en textos nacionales como internacionales, esto es Ley 14/2014, de 24 de julio de la Navegación Marítima y el Convenio Internacional sobre los privilegios marítimos y la hipoteca naval de Ginebra de 1993.
\end{abstract}

Abstract: It is our purpose to analyze the procedural protection that our legal system grants to the maritime claims, as credits of a special nature that exist, both nationally and internationally, 
since ancient times, as a mechanism to facilitate the financing of maritime trade, because they grant to these creditors some special privileges for the satisfaction of their credits. To do this, we will begin by determining the most relevant aspects of its legal configuration, in order to subsequently address the procedural protection that these credits receive, focusing, not only on analyzing the different actions that these creditors can exercise to defend their rights, if not also, how can they enforce these credits against other creditors who have initiated an execution process in which the ship that serves as a guarantee for the credits has been or could be seized, also establishing, in what order should they be satisfied.

We will also go deeper, determining the credits that are considered privileged maritime credits, the different types that exist and analyzing the procedural specialties that are contained in both national and international texts, this is Ley 14/2014, de 24 de julio de la Navegación Maritima and the International Convention on Maritime Liens and Mortgages, Geneva, 6 May 1993.

Palabras claves: créditos marítimos, privilegios marítimos, prelación de créditos marítimos, tutela procesal, acciones ejercitables.

Keywords: maritime claims, maritime liens, priority, maritime liens execution, procedural protection, actions.

Sumario: 1. INTRODUCCIÓN. 2. LOS CRÉDITOS MARÍTIMOS PRIVILEGIADOS. 2.1. Naturaleza jurídica del privilegio marítimo. 2.2. Regulación legal, nacional e internacional. 2.3. Efectos generales del privilegio. 2.4. Los créditos con privilegio marítimo. 2.5. Extinción del privilegio. 3. RECONOCIMIENTO Y EJECUCIÓN DEL PRIVILEGIO. 3.1. Acciones ejercitables en relación a los créditos marítimos privilegiados. 3.2. La realización del privilegio. 3.2.A. La venta forzosa del buque. 3.2.B. Destino de la suma obtenida con la venta forzosa del buque. 3.3. Los créditos marítimos privilegiados en los procesos ejecutivos iniciados por un tercero. 3.3.A. El orden de prelación de créditos en la ejecución del buque. 3.3.B. Las tercerías de mejor derecho. 4. CONCLUSIONES. 5. BIBLIOGRAFÍA.

\section{INTRODUCCIÓN}

Resulta una cuestión de vital importancia para el desarrollo del comercio marítimo, que quienes se dedican al armamento y explotación de buques mercantes o actividades marítimas, puedan acudir a créditos o productos financieros que les permitan avanzar en su negocio. Estamos, en estos casos, ante los conocidos créditos marítimos que, lejos de poder ser considerados simplemente como parte del concepto de crédito o producto financiero general, revisten una especial configuración y tratamiento legal, pues, normalmente, la garantía principal o incluso única de dichos créditos es la aeronave o buque en sí mismo, buque que, como resulta obvio, se caracteriza por su movilidad, lo que conlleva que los acreedores de dichos créditos se encuentren con especiales dificultades de seguimiento y localización, del que, sin embargo, es su principal objeto de garantía, y, por tanto, del cobro de sus créditos marítimos.

Surgen así, como consecuencia de estas especiales circunstancias, los denominados privilegios maritimos o créditos marítimos privilegiados, con el firme objetivo de 
disminuir estos inconvenientes, y facilitar a dichos acreedores el derecho de realización preferente de tales créditos frente a otros acreedores ordinarios del naviero, para así poder garantizar el cobro de los mismos ${ }^{1}$. Podemos definir, por tanto, a los privilegios marítimos como aquellos créditos que le otorgan a su titular la facultad de perseguir y realizar de forma preferente la venta judicial del buque que se encuentre especialmente afecto en garantía de éstos ${ }^{2}$.

Debe, no obstante, tenerse en cuenta a este respecto que, lejos de suponer la existencia de estos privilegios marítimos simplemente un criterio de ordenación de acreedores, su existencia y reconocimiento implica una auténtica revolución en los principios y conceptos generales del Derecho Crediticio, lo que conlleva por supuesto, un efecto reflejo, en los del propio Derecho Procesal, en relación al ejercicio del derecho de realización, como tendremos ocasión de comprobar a lo largo de estas páginas.

A este respecto, nos parece oportuno partir de la clásica distinción entre tutela declarativa y tutela ejecutiva. Ambas intensamente relacionadas, pero no dependientes, pues, como es sabido, no a todo proceso declarativo le sigue un proceso ejecutivo, ni todo proceso ejecutivo va precedido de un proceso declarativo ${ }^{3}$. Tendremos, por tanto, como objetivo, a través de este estudio, analizar si uno de los efectos que lleva aparejado estos créditos, es la posibilidad de ejercitar directamente una acción ejecutiva, y en su caso, ver a través de que procedimiento, o si, por el contrario, debe ejercitarse de forma previa una acción declarativa y, una vez resuelta ésta con éxito y conseguido un título ejecutivo procesal, entonces, iniciar el correspondiente proceso de ejecución para obtener la realización y satisfacción del crédito.

Se trata así, por tanto, de determinar en que consiste, realmente, ese derecho de realización que forma histórica se atribuye a los privilegios marítimos.

Pero, además, no resulta infrecuente, tal y como acabamos de apuntar, en el ámbito del Derecho Marítimo, y más concretamente, en relación al comercio marítimo, financiar dichas actividades, partiendo incluso de la propia construcción buque o aeronave, acudiendo a la constitución de créditos o préstamos de muy distinta naturaleza. Es más, incluso, puede suceder que, por el propio devenir de la actividad comercial, surjan créditos a los que hacer frente y responsabilidades de las que responder, en su caso, con el propio buque, por lo que, podemos entonces, en este punto, preguntarnos, no sólo que cual es la prelación de créditos, es decir, la preferencia en el orden de cobro de dichos créditos, si no, también, como puede afectar esta situación al ejercicio de la tutela

\footnotetext{
${ }^{1}$ Vid. RUIZ SOROA, J.M., "Los privilegios marítimos", en AA.VV.. Preferencias de créditos, Manuales de formación continuada 2, Consejo General del Poder Judicial, Madrid, 2000, pp. 313 a 315.

${ }^{2}$ En este sentido, vid. GABALDÓN GARCÍA, J.L., Los privilegios marítimos sobre el buque, tesis doctoral presentada en Madrid en 1992, pp. 217 y 218.

${ }^{3}$ Vid. ROBLES GARZÓN, J.A., "La función jurisdiccional”, en AA.VV., Conceptos de Derecho Procesal Civil, Madrid, Tecnos, 1ªed., 2017, pág. 53.
} 
correspondiente por parte de los acreedores, especialmente, de los titulares de créditos marítimos privilegiados.

Por todo ello, nos proponemos a continuación, analizar las características más importantes de los créditos marítimos privilegiados, así como las posibles acciones que pueden ejercitarse, y el mecanismo a través del cual, hacer valer en la tramitación procesal de la satisfacción de créditos, la existencia de dichos privilegios o el orden a tener en cuenta entre ellos, según el caso.

\section{LOS CRÉDITOS MARÍTIMOS PRIVILEGIADOS}

\subsection{Los créditos con privilegio marítimo}

Los créditos marítimos reconocidos como privilegiados, se recogen en el artículo 4 del citado Convenio de Ginebra, siendo éstos:

a) Los créditos por los sueldos y otras cantidades debidos al capitán, los oficiales y demás miembros de la dotación del buque en virtud de su enrolamiento a bordo del buque, incluidos los gastos de repatriación y las cuotas de la seguridad social pagaderas en su nombre 4 .

b) Los créditos por causa de muerte o lesiones corporales sobrevenidas, en tierra o en el agua, en relación directa con la explotación del buque

c) los créditos por la recompensa pagadera por el salvamento del buque

d) los créditos por derechos de puerto, de canal y de otras vías navegables y practicaje.

e) los créditos nacidos de culpa extracontractual por razón de la pérdida o el daño materiales causados por la explotación del buque distintos de la pérdida o el daño ocasionados al cargamento, los contenedores y los efectos del pasaje transportados a bordo del buque.

No obstante, el Convenio permite que los Estados parte puedan conceder en virtud de su legislación, otros privilegios marítimos sobre un buque para garantizar créditos, distintos de los mencionados, ya sea contra el propietario, el arrendatario a casco desnudo, el gestor o el naviero del buque. Para ello, se requiere:

- Que esos privilegios sigan al buque a pesar de cualquier cambio de propiedad, matrícula o pabellón;

- Que no puedan, los acreedores marítimos privilegiados, subrogarse en los derechos del propietario del buque a la indemnización debida en virtud de un contrato de seguro;

- Que se respete el pago previo de las costas procesales y de los gastos originados por el embargo preventivo o por la ejecución y subsiguiente venta del buque.

\footnotetext{
${ }^{4}$ Sobre el privilegio sobre la flota, vid. RUEDA MARTÍNEZ, J.A., "Los privilegios marítimos", en AA.VV. Ley de la navegación marítima, balance de su aplicación práctica. Madrid, Marcial Pons, 2019, pág. 1235 y 136.
} 
Además, dichos créditos privilegiados, deben extinguirse o bien a la expiración de un plazo de seis meses contados desde el nacimiento de los créditos garantizados, a menos que, antes del vencimiento de ese plazo, el buque haya sido objeto de embargo preventivo o ejecución conducentes a una venta forzosa; o al final de un plazo de sesenta días después de la venta del buque a un comprador de buena fe, que empezará a correr desde el día en que se inscriba la venta en el registro, de conformidad con la legislación del Estado en que esté matriculado el buque después de la venta, si este plazo venciere antes que el señalado en el inciso anterior.

Por último, dichos créditos marítimos privilegiados regulados por cada Estado parte en su legislación interna, deben posponerse a los privilegios marítimos enumerados en Convenio, así como a las hipotecas, cargas o gravámenes inscritos.

Por su parte, a nivel nacional, el artículo 124 LNM, reconoce igualmente esta posibilidad, pues según éste, pueden recaer también sobre el buque cualesquiera otros privilegios reconocidos por el Derecho común o leyes especiales, pero tales privilegios, sea cual fuere el rango de prelación que le otorguen las leyes que los reconozcan, serán graduados tras las hipotecas y demás cargas y gravámenes inscritos. Es más, atendiendo al principio de reciprocidad, podrán ser reconocidos otros privilegios marítimos que graven buques extranjeros con arreglo a la ley del pabellón, aunque dichos créditos, irán situados igualmente tras las hipotecas y demás cargas y gravámenes inscritos.

\subsection{Naturaleza jurídica del privilegio marítimo}

El privilegio marítimo que acompaña al crédito, posee, sin lugar a dudas, una naturaleza accesoria, respecto a éste ${ }^{5}$. Precisamente por su naturaleza accesoria, si se realiza la cesión o subrogación en el derecho, se entiende modificada también la titularidad sobre el privilegio, y si se produce la extinción del crédito al que acompañan, se considera extinguido también el privilegio ${ }^{6}$.

Así se establece expresamente en el artículo 10.1 del Convenio Internacional sobre los privilegios marítimos y la hipoteca naval, hecho en Ginebra el 6 de mayo de 1993 (En adelante, CPH 1993), al afirmar que, tanto la cesión de un crédito garantizado con un privilegio marítimo como la subrogación en los derechos del titular del tal crédito, supone simultáneamente la cesión de ese privilegio marítimo o la subrogación en los derechos que este lleva aparejados.

De igual modo, podemos entonces afirmar, respecto de la extinción del crédito, que los privilegios se extinguen junto con el crédito al que acompañan, de manera que, una vez extinguido el crédito, cualquiera que sea la causa o el motivo, se considera extinguido también el privilegio.

\footnotetext{
${ }^{5}$ En este sentido, vid. RUIZ SOROA, J.M., "Los privilegios marítimos”, op. cit. p. 362.

${ }^{6}$ Para un análisis en profundidad sobre la naturaleza y características del privilegio, vid. DÍEZ SOTO, C.M., "Los privilegios crediticios como mecanismo de protección del crédito", en AA.VV., Preferencias de créditos, Manuales de formación continuada 2, Consejo General del Poder Judicial, Madrid, 2000, pp. 23 ss.
} 


\subsection{Regulación legal nacional e internacional}

Como decíamos al principio de estas páginas, una de las principales características del Derecho Marítimo es su internacionalidad, pues se trata, sin duda alguna, de una rama del Derecho relacionada con el comercio y el tráfico marítimo y, lógicamente, estos alcanzan su máxima plenitud al desarrollarse en ámbitos internacionales, generando así, diversos y complejos negocios jurídicos entre los diversos Estados implicados.

No resulta de extrañar, por tanto, que estos privilegios no sólo cuenten con regulación propia de cada Estado al respecto, sino que, sea la normativa desarrollada a nivel internacional la fuente legal más importante en esta materia, por lo que desde mitad del siglo XIX surgen diversas comisiones internacionales para el estudio del Derecho Marítimo Internacional ${ }^{7}$. La más importante fue, sin duda, el Comité Marítimo Internacional (En adelante, el CMI), cuyos trabajos dieron sus frutos en los Convenios de Bruselas de 1926 y 1967, y en el ya citado Convenio de Ginebra de $1993^{8}$.

A nivel nacional, estos créditos se regulan actualmente en los artículos 122 a 125 de la Ley 14/2014, de 24 de julio de la Navegación Marítima (En adelante, LNM), y a nivel internacional, destaca sin duda como instrumento jurídico básico el citado CPH 93.

Respecto al CPH 93, debemos destacar que supuso una importante limitación en torno a los créditos considerados con privilegio marítimo, con el objetivo fundamental de reforzar las ventajas reconocidas a la hipoteca naval, pues la existencia de excesivos privilegios, supone un atentico perjuicio para el acreedor hipotecario, ya que el cobro de su crédito, a pesar de estar privilegiado, se ve sin embargo, superado por el pago previo y preferente de los demás créditos marítimos privilegiados, y eso aun cuando resulta razonable afirmar, que es, precisamente este instrumento financiero, la hipoteca naval, el que permite financiar en muchos ocasiones dicha actividad comercial ${ }^{9}$.

\subsection{Efectos generales del privilegio}

Teniendo en cuenta el fundamento que sirvió de base a su creación, esto es, disminuir el riesgo al que se enfrentan determinados acreedores del naviero cuyos créditos han sido garantizados con la existencia del buque o aeronave, facilitándoles un derecho de realización preferente de tales créditos frente a otros acreedores ordinarios, para así poder

\footnotetext{
${ }^{7}$ Instituciones como la Conferencia de las Naciones Unidas sobre Comercio y Desarrollo (En adelante, UNCTAD) y la Organización Marítima Internacional (En adelante, OMI) hicieron importantes aportaciones a dichos Convenios. Más adelante, la Comisión de Transporte Marítimo de la Conferencia sobre Comercio y Desarrollo de las Naciones Unidas junto a la OMI creó el denominado Grupo intergubernamental mixto de expertos en privilegios marítimos e hipoteca naval y cuestiones conexas, conocido como JIGE.

${ }^{8}$ El Convenio Internacional para la unificación de ciertas reglas relativas a los privilegios marítimos e Hipotecas marítimas, celebrado en Bruselas en 1926 (en adelante CPH 26), estuvo en vigor hasta 2004, pero el Convenio Internacional sobre Privilegios Marítimos e Hipotecas marítimas, celebrado en Bruselas en 1967 (en adelante, CPH 67), no llegó realmente a entrar en vigor ya que no alcanzó el número de ratificaciones necesarias para ello. Aun así, deben ser tenidos en cuenta como precedentes legislativos de gran importancia, pues su evolución y desarrollo nos han llevado hasta la regulación actual.

${ }^{9}$ En este sentido, vid. RUIZ SOROA, J.M., “Los privilegios marítimos”, op. cit. pp. 316 y 317.
} 
garantizar el cobro de los mismos, podemos afirmar, que el reconocimiento de un crédito como privilegio marítimo conlleva, fundamentalmente, las siguientes consecuencias:

a) Quebrantamiento del clásico principio par conditio creditorum

Resulta ampliamente conocido en nuestro Derecho el principio par conditio creditorum, en virtud del cual, debe otorgarse a todos los acreedores que concurren a satisfacer su deuda respecto de un mismo deudor, iguales condiciones frente al cobro de su crédito.

Sin embargo, lo cierto es que también es ampliamente conocido que en nuestro ordenamiento existen normas que clasifican los distintos tipos de créditos existentes en nuestro Derecho y, una vez clasificados, establecen un orden de prelación, es decir, de preferencia en el cobro de los mismo, de manera que, si bien es cierto que la igualdad entre acreedores debe respetarse, no es menos cierto que esta igualdad opera solo entre acreedores cuyos créditos pertenezcan a la misma categoría, pero no entre aquellos que no corresponden al mismo rango legal ${ }^{10}$. Ponemos en duda, por tanto, que el principio par conditio creditorum, aunque ciertamente se aplica de forma general, sea exclusivo del Derecho Marítimo y suponga una especialidad propia de los créditos marítimos privilegiados $^{11}$.

En el caso de los créditos marítimos, establecen los artículos 5.1 CPH93 y el 122.2 LNM, que los privilegios marítimos gozan de preferencia sobre las hipotecas y demás cargas y gravámenes inscritos, cualquiera que sea la fecha de su inscripción, sin que ningún otro crédito pueda anteponerse a tales privilegios, a excepción, por supuesto, del pago de las costas procesales y de los gastos originados por el embargo preventivo o por la ejecución y subsiguiente venta del buque y los gastos que hayan de abonarse a la Administración Marítima por la remoción de buques naufragados o hundidos.

Puede decirse, por tanto, que la existencia de estos privilegios conlleva para el a creedor titular, un derecho de preferencia para ver satisfecho su crédito en caso de venta judicial del buque sobre el que se constituyó, de forma previa a los demás acreedores, si los hubiere, incluso en caso de existencia de acreedor hipotecario ${ }^{12}$.

b) Establecimiento de la reipersecutoriedad

El reconocimiento de la existencia de estos créditos privilegiados, supone, entre otras cosas, constituir una auténtica garantía real sobre dicho buque, pues surge la existencia

\footnotetext{
${ }^{10}$ Encontramos, en este sentido, los artículos 1921 a 1929 del Código civil (en adelante, Cc.), y también los artículos 269 a 284 del Real Decreto Legislativo 1/2020, de 5 de mayo, por el que se aprueba el Texto Refundido de la Ley Concursal (en adelante, TRLC), para los casos en que el procedimiento a seguir en caso de concurrencia de acreedores, sea el proceso concursal.

${ }^{11}$ En idéntico sentido se pronuncia CASAS ROBLA, J., quien señala que "Desde que existen las obligaciones, existen distintas formas de exigencia de las mismas y, para no remontarnos a otros ordenamientos jurídicos, no es lo mismo responder de la deuda con la propia palabra (sponsio) que responder con el propio cuerpo, pudiendo ser esclavizado por el acreedor (manus iniectio, LXII Tablas, III, 1 a 6). Vid. CASAS ROBLA, J., "Los privilegios marítimos", en AAVV., Comentarios a la Ley de la Navegación Marítima, Madrid, Dykinson, 2015, pág. 92.

${ }^{12}$ De ahí que, como decíamos anteriormente, el CPH 1993, priorizase reducir los créditos considerados con privilegio marítimo, con el objetivo fundamental de reforzar las ventajas reconocidas a la hipoteca naval.
} 
de un derecho de persecución sobre el bien gravado, de manera que le sigue incluso aún cuando dicho bien haya salido del patrimonio del deudor.

Así lo establecen los artículos 8 CPH 93 y 122.2 LNM, según los cuales, los privilegios marítimos gravan el buque sin necesidad de publicidad registral, y le siguen a pesar del cambio de propiedad, matrícula o pabellón. Significa esto que ni el cambio de propietario, de matrícula ni de pabellón extinguen el privilegio del acreedor del crédito marítimo privilegiado, por lo que puede afirmarse que, sin lugar a dudas, se trata de una garantía real. Supone esto que ni siquiera la venta del buque es oponible al acreedor privilegiado.

c) No aplicación del derecho de retención de otros acreedores

Según el artículo 7.1 CPH 93, todo Estado parte podrá conceder con arreglo a su legislación interna, un derecho de retención respecto de un buque que se halle en posesión de un constructor o reparador de buques, para garantizar los créditos originados por la construcción o reparación del mismo, mientras esté en su posesión ${ }^{13}$.

Esta disposición se debe a que tradicionalmente, se ha reconocido en las legislaciones nacionales un derecho de retención a favor de estos acreedores, lo que en la práctica suponía un contratiempo importante respecto al derecho de cobro preferente de los acreedores de privilegios marítimos, pues los constructores y reparadores, tenían reconocido el derecho a retener el buque hasta que se les pagase su crédito.

Siendo así, el CPH 93, soluciona la cuestión respetando el derecho de los acreedores titulares de créditos marítimos privilegiados, pues en el artículo 12.4, establece que, en caso de existir un derecho de retención reconocido a favor de un constructor o reparador de buques, por la legislación nacional del Estado parte en que se realiza la venta judicial del buque, el constructor o reparador de buques deberá entregar al comprador la posesión del buque, pero podrá obtener el pago de su crédito una vez satisfechos los créditos de los titulares de los privilegios marítimos de origen internacional.

Esto significa que, en caso de existir créditos marítimos privilegiados, de una parte, y créditos por construcción o reparación del buque que tengan reconocido por el Estado en el que se lleva a cabo la venta judicial del buque, un derecho de retención, por otra, estos últimos están obligados a entregar la posesión del buque, obteniendo a cambio, el beneficio de situar su crédito justamente tras el pago de los privilegios marítimos internacionales, quedando, incluso por delante, del pago de la hipoteca naval, y otras cargas y gravámenes inscritos, así como de los privilegios marítimos de origen nacional propios de cada Estado.

En lo que respecta a la legislación española, el artículo 139 LNM recoge esta regulación, aunque matiza que sólo será aplicable respecto al constructor cuando en virtud de pacto

\footnotetext{
${ }^{13}$ Vid. VELASCO NATES, A., "El derecho de retención de la mercancía como garantía del pago del flete, demoras y otros gastos en la Ley de la Navegación Marítima", en AA.VV., Comentarios a la Ley de la Navegación Marítima, Madrid, Dykinson, 2015, pp. 197 a 211.
} 
la propiedad del buque pertenezca al comitente, lo cual supone un dato importante, ya que exige al comitente ser el propietario del buque.

\subsection{Extinción del privilegio}

Decíamos con anterioridad, al tratar la naturaleza jurídica de los privilegios marítimos, que se trataba de un derecho accesorio, de forma que éstos se extinguen junto con el crédito al que acompañan, por lo que, una vez extinguido el crédito, cualquiera que sea la causa o el motivo, se considera extinguido también el privilegio ${ }^{14}$.

Ahora bien, esto no significa que no pueda ocurrir a la inversa, esto es, que se extinga el privilegio, pero no el crédito al que acompaña, pues el propio privilegio puede verse afectado por causas de extinción propias e independientes. Podemos distinguir, por tanto, entre causas de extinción del crédito marítimo privilegiado y causas de extinción del privilegio en sí mismo.

Así, según el artículo 9 CPH 93, los privilegios marítimos se extinguen por el transcurso de un año a menos que, antes del vencimiento de ese plazo, el buque haya sido objeto de embargo preventivo o ejecución conducentes a una venta forzosa. La extinción del privilegio, por tanto, no supone la extinción del crédito, al que resultará aplicable el plazo que establezca la legislación nacional para dicho tipo de crédito en cuestión. Por tanto, debe entenderse que, transcurrido un año, el crédito es reclamable si los plazos de la legislación nacional que regula tal crédito lo permiten, pero no le será de aplicación el régimen jurídico establecido por el CPH 93, ni por la LNM para los créditos marítimos privilegiados.

Existen, a este respecto, dos cuestiones importantes a determinar: el momento de inicio del cómputo de dicho plazo y la naturaleza de prescripción o caducidad del mismo.

Respecto al inicio del cómputo del plazo, el propio artículo 9 hace referencia a dos momentos distintos, según el crédito privilegiado al que afecte. Así, si se trata de créditos laborales debidos a la tripulación, el plazo comenzará a contar desde el momento en que haya terminado el enrolamiento del acreedor a bordo del buque, mientras que, si se trata de créditos por muertes y lesiones, créditos por salvamento marítimo, créditos de puerto y practicaje, y créditos por daños por culpa extracontractual, el plazo comenzará a contar, desde la fecha de nacimiento de los créditos que esos privilegios garanticen ${ }^{15}$.

En cuanto a si se trata de un plazo de prescripción o caducidad, debemos decantarnos por la primera opción, en tanto que, el mismo apartado 1 de dicho artículo 9 CPH 93, establece que "a menos que, antes del vencimiento de ese plazo, el buque haya sido objeto de embargo preventivo o ejecución conducentes a una venta forzosa”. Vemos, por tanto, de

\footnotetext{
14 Vid. RUEDA MARTÍNEZ, J.A., "Los privilegios marítimos", en AA.VV., Comentarios sobre la ley de la navegación marítima, Madrid, Marcial Pons, 2015, pág. 193 y 194.

${ }^{15}$ Por su parte, el artículo 123.2 y 123.3 LNM, recogen, respecto a los privilegios sobre la flota, el mismo plazo de extinción del privilegio, especificando que éste comenzará a contar desde que se extingue el contrato de embarque del acreedor con la empresa o grupo empresarial.
} 
la literalidad del artículo, que se trata de un plazo de prescripción, pues puede interrumpirse única y exclusivamente, en principio, por el embargo preventivo o ejecución del buque, tendentes a la venta forzosa.

Cuestión distinta es plantear la posibilidad de dejar en suspensión este plazo, pues, de la misma manera que cuando se trata de créditos laborales, no comenzará a contar hasta que la tripulación no desembarque, podríamos entender también que, respecto a los demás privilegios marítimos, se puede suspender el plazo de prescripción por no poder proceder al embargo preventivo o a la ejecución del buque por imperativo legal, ya que es lo único que permitiría interrumpir dicho plazo.

\section{RECONOCIMIENTO Y EJECUCIÓN DEL PRIVILEGIO}

Una vez analizados los aspectos sustantivos más importantes relacionados con los créditos marítimos privilegiados, debemos ahora abordar su perspectiva procesal, concretamente, respecto al reconocimiento y ejecución de los mismos. No obstante, debe advertirse, en primer lugar, que no es éste un objetivo sencillo, ya que nos encontramos, como expondremos a continuación, con distintas situaciones jurídicas que pueden dar lugar a la tramitación de distintos tipos de procesos, tanto declarativos como ejecutivos, por lo que la venta judicial del buque puede finalmente realizarse a través de un proceso ordinario de ejecución, o como consecuencia de un proceso de ejecución hipotecaria, y en todas ellas, habrá que tener en cuenta la existencia de estos créditos privilegiados para darles el tratamiento procesal que resulte adecuado según el caso.

\subsection{Acciones ejercitables en relación a los créditos marítimos privilegiados}

Como norma general, suele afirmarse que una de las características que presentan los créditos marítimos privilegiados es su ejecutoriedad, de manera que, el titular de estos créditos puede satisfacer su crédito accediendo directamente a un proceso ejecutivo, sin necesidad de ejercitar previamente una acción declarativa a través del proceso correspondiente ${ }^{16}$. Podríamos pensar que esta afirmación se basa en el propio $\mathrm{CPH} 93 \mathrm{y}$ en los artículos 480 ss LNM, pero, a nuestro entender, la regulación de los créditos marítimos privilegiados en ambos textos se limita, exclusivamente, a determinar las especialidades que afectan a los mismos, pero no regula ni prevé ningún mecanismo especial para su ejecución.

Así, podemos decir que el CPH 93 básicamente, lo que hace es establecer cuáles son esos créditos, que requisitos deben cumplir, y que posición ocupan, de preferencia, respecto a los demás créditos de otra naturaleza; y en cuanto a su venta forzosa, se ocupa de establecer ciertas especialidades respecto a la notificación y efectos. Pero nada más.

Tendríamos que acudir, entonces a nuestra LNM para analizar esta cuestión. Pero, nuestra LNM se limita, igualmente, en los artículos 480 ss, a establecer determinadas normas especiales respecto a la forma de llevar a cabo la venta forzosa del buque, ya que, si bien

\footnotetext{
${ }^{16}$ En este sentido, vid. CASAS ROBLA, J. "Los privilegios marítimos”, op.cit., pág. 102.
} 
se remite a estos efectos a la Ley de Enjuiciamiento Civil (En adelante, LEC), recoge ciertas especialidades que deben tenerse en cuenta. Y tampoco en los artículos 122 a 125 de la misma, se regula ningún procedimiento específico para ejecutar estos créditos, pues, sencillamente, se recoge lo establecido en el $\mathrm{CPH}$ 93, respecto a los requisitos y preferencia en el cobro respecto a otros créditos.

Por tanto, a nuestro entender, actualmente, no puede llegarse de forma clara a la conclusión de que los créditos marítimos privilegiados son, generalmente, ejecutables de forma directa sin necesidad de ejercitar una acción declarativa previa, pues, ya que la LNM no prevé un proceso ejecutivo propio para ellos, resultaría de aplicación para su ejecución la $\mathrm{LEC}^{17}$. En ella, como es sabido, se regula o bien el proceso ordinario de ejecución o bien el denominado proceso de ejecución hipotecaria, que prevé ciertas especialidades sobre el primero. Respecto al proceso de ejecución hipotecaria, éste está reservado exclusivamente a aquellas deudas garantizadas con prenda o hipoteca, por lo que no pueden ser una vía de ejecución para los créditos marítimos privilegiados, quedando, entonces, únicamente abierta la posibilidad de tramitar un proceso ordinario de ejecución.

Ahora bien, para poder iniciar el proceso de ejecución ordinario, la LEC contempla como requisito obligatorio de acceso al mismo, disponer de un título ejecutivo, pudiendo ser éste procesal o no procesal. Ni que decir tiene que, la falta de formalidad que se exige en la constitución de estos créditos, como hemos visto, hace que, como norma general, éstos no estén constituidos mediante un documento reconocido como título ejecutivo en el artículo 517 LEC, por lo que, entonces no sería posible iniciar este proceso. Es más, en este sentido, nos plantearíamos como única posibilidad, acudir al apartado noveno de dicho artículo, en el que se produce, al enumerar los títulos ejecutivos, una remisión a otras normas en las que pueda estar contemplada la existencia de otros documentos que lleven aparejada ejecución. Pero, entendemos que no es el caso, ya que, ni el CPH 93 ni la LNM otorgan expresamente, como hemos visto, a estos créditos ni a los documentos que sirven de base a su constitución, carácter ejecutivo, pues en ninguno de estos textos se dice nada relacionado con este carácter, sino que se limita a establecer el orden de cobro y las especialidades a tener en cuenta cuando se produzca la venta forzosa del buque.

Es, por todo esto que, a nuestro entender, podemos encontrarnos, por tanto, con créditos marítimos privilegiados que, a pesar de no exigirse, sí estén constituidos a través de

\footnotetext{
${ }^{17}$ En el mismo sentido, vid. DEL CORTE LÓPEZ, J., "Especialidades procesales en la Ley de la navegación marítima", en AA.VV. Comentarios sobre la ley de la navegación marítima, Madrid, Marcial Pons, 2015, pág. 771; VEIGA COPO, A.B., "Privilegios sobre buques y aeronaves", en AA.VV., Enciclopedia de Derecho Concursal, t.II, Navarra, Cizur menor, Aranzadi, 2012, pág. 2359 ss; ALONSO LEDESMA, C., "Viejos y nuevos problemas de los privilegios marítimos", en AA.VV., Estudios de Derecho Marítimo, Navarra, Cizur Menor, Aranzadi, 2012, pág. 311; DOMÍNGUEZ CABRERA, M.P., "La ejecución extraconcursal del buque", Anuario de Derecho Marítimo, núm. 27, 2010, pág. 163; PULIDO BEGINES, J.L., Instituciones de Derecho de la Navegación Marítima, Madrid, Tecnos, 2009, pág. 240; GABALDÓN GARCÍA, J.L. Y RUÍZ SOROA, J.M., Manual de Derecho de la Navegación, Marítima, Madrid, Marcial Pons, 2006, pág. 942.
} 
documentos que llevan a aparejada ejecución, y otros muchos casos, como suele ser lo habitual por la propia naturaleza y origen de muchos de estos créditos, en los que no están reconocidos en títulos ejecutivos ${ }^{18}$.

Siendo así, podemos afirmar entonces que, en la mayoría de casos, para poder solicitar la venta forzosa del buque, será necesario que los acreedores titulares de estos créditos marítimos privilegiados, ejerciten, en primer lugar, la acción declarativa que corresponda, e inicien el correspondiente proceso declarativo, a cuya finalización puedan obtener un título ejecutivo de carácter procesal que les permita, ahora sí, ejercitar la correlativa acción ejecutiva e iniciar el proceso ejecutivo en el que llevar a cabo, en su caso, la venta forzosa del buque ${ }^{19}$.

No obstante, y en contra de esta opinión, se ha dicho que puede considerarse a estos créditos como hipotecas legales tácitas sobre el buque, de manera que, su constitución, lleva aparejada ejecución y otorga al acreedor titular del mismo un derecho de realización forzosa directo sobre el mismo, sin necesidad de acción declarativa previa, como cualquier derecho de garantía ${ }^{20}$. Esto supondría entonces admitir que, estos créditos marítimos privilegiados o bien, permiten el ejercicio de dicha acción ejecutiva a través del proceso hipotecario, ya que son hipotecas legales tácitas, o bien otorgan la posibilidad, al menos, de iniciar un proceso ejecutivo ordinario de forma directa ${ }^{21}$.

Sin embargo, y como acabamos de exponer, en nuestra opinión esta opción no resulta técnicamente la más adecuada, desde la perspectiva procesal, lo cual no significa que no pueda ser la opción más práctica y/o deseable de cara a la protección del acreedor privilegiado. Y esto es así porque, aunque reconozcamos a estos créditos como hipotecas, para poder ejercitar una acción que inicie un proceso de ejecución hipotecaria, en virtud del artículo 682.2 LEC, es necesario que el crédito cumpla dos requisitos: el primero, que en la escritura de constitución de la hipoteca se determine el precio en que los interesados

\footnotetext{
${ }^{18}$ Debemos excluir de esta afirmación los créditos por derechos de puerto establecidos en el artículo 4.d) CPH 93, pues en este caso, bastaría con la certificación de la cuantía del crédito realizada por la propia Administración para poder ejecutarse a través del procedimiento administrativo correspondiente.

${ }^{19}$ El procedimiento declarativo a seguir dependerá, así mismo, del crédito de que se trate, pues pueden ser éstos de distinta naturaleza.

${ }^{20}$ En este sentido, se pronuncia claramente CASAS ROBLA: "Nosotros consideramos que los privilegios marítimos son una categoría específica hipotecas legales tácitas sobre el buque, esto es, que carecen de autonomía conceptual sobre cualquier otra hipoteca o prenda legalmente establecida, por ello son reipersecutorios, por ello llevan aparejada la realización mediante ejecución forzosa del buque y por ello se anteponen incluso a la hipoteca naval y las demás garantías convencionales constituidas voluntariamente sobre el buque por el propietario del mismo. También por ello tienen existencia incluso aunque el deudor no sea el propietario del buque y no necesitan inscripción. CASAS ROBLA, J. "Los privilegios marítimos", op. cit., pág. 94.

${ }^{21}$ Este mismo autor, CASAS ROBLA, en congruencia a la tesis que mantiene, afirma que "Al tratarse de créditos con acción real aparejada, ello supone que el acreedor puede, sin necesidad de acción declarativa previa, acudir directamente al procedimiento ejecutivo correspondiente que en la tradición marítima (tanto continental como anglosajona) significa un derecho inmediato de venta forzosa del buque, un «ius vendendi» aparejado a cualquier derecho real de garantía: fiducia, prenda e hipoteca”. CASAS ROBLA, J. "Los privilegios marítimos”, op. cit., pág. 102.
} 
tasan el bien hipotecado, para que sirva de tipo en la subasta; y el segundo, que en dicha escritura, conste un domicilio, que fijará el deudor, para la práctica de los requerimientos y de las notificaciones.

Esto significa, como resulta obvio, que, para poder acudir a un proceso de ejecución hipotecaria, es requisito indispensable que el crédito conste en escritura pública, la cual, debe, además, adjuntarse a la demanda ejecutiva a través de la cual se quiera iniciar este procedimiento, en virtud del artículo 685.1 LEC, pudiendo ser sustituida, en determinadas circunstancias y respecto a ciertos créditos hipotecarios, por una certificación registral.

Puede observarse así, como, aún reconociendo esta naturaleza a los créditos con privilegio marítimo, no sería posible iniciar un proceso de ejecución hipotecaria para ejercitar el supuesto derecho de realización que conllevan ni reclamar la satisfacción de su crédito ni la venta judicial del buque a través de éste, pues no cumple con los requisitos ni las formalidades legalmente establecidas en los artículos 681 y siguientes LEC.

Por tanto, esto nos tendría que llevar a afirmar que, excluida la posibilidad de acudir al proceso hipotecario, podría entonces el titular del crédito marítimo privilegiado, poder acudir directamente a un proceso ordinario de ejecución, y ejercitar así su derecho de realización directa, pero esto, como acabamos de exponer, tampoco va a resultar posible como norma general, ya que, normalmente, estos créditos, ni por la falta de exigencia de requisitos formales para constituirse ni, en muchos casos, por el propio origen de dichos créditos- piénsese, por ejemplo, en los créditos por causa de muerte o lesiones corporales sobrevenidas, en tierra o en el agua, en relación directa con la explotación del buque, que hacen referencia a una responsabilidad extracontractual-, están formalizados en un documento que tenga atribuida fuerza ejecutiva, ni por el artículo 517 LEC, ni, como ya hemos expuesto, por la remisión del apartado noveno de la misma a la LNM, pues, reiteramos que, en nuestra opinión, no puede deducirse intención alguna del legislador, al redactar la LNM, de conceder tal fuerza a estos créditos o documentos, teniendo en cuenta, además, que pueden éstos ser muy diversos y también de naturaleza muy diversa, en función del crédito del que se trate ${ }^{22}$.

Ahora bien, también resulta conveniente recordar, en cualquier caso, que, aún cuando se admitiese que estos créditos son ejecutables de forma directa a través del proceso de ejecución, esto no supone excluir o limitar la posibilidad que tiene el titular de dicho crédito de acudir, si así resulta conveniente, a un proceso declarativo, con lo que, incluso así, debemos tener en cuenta, que los titulares de estos créditos pueden ejercitar de una acción declarativa como paso inicial para la satisfacción de su crédito.

\footnotetext{
${ }^{22}$ Un supuesto de título ejecutivo extrajudicial reconocido en la LNM es, por contraposición, el conocimiento de embarque, aunque una deficiente regulación procesal no permite tampoco, en este caso, hacer uso del privilegio del acreedor titular de este documento. Vid, a mayor abundamiento, FONTESTAD PORTALÉS, L., Conocimiento de embarque como título ejecutivo, Titant Lo Blanch, Valencia, 2007, pág. 370 ss, y, FONTESTAD PORTALÉS, L., Navegando hacia el futuro: propuestas de reformas procesales en la LNM y el impacto de la inteligencia artificial en el transporte marítimo, Navarra, Aranzadi, 2021, pág. 126 ss.
} 


\subsection{La realización del privilegio}

Como acabamos de exponer, para poder llevar a cabo la venta forzosa del buque a través de un proceso de ejecución, los titulares de los créditos marítimos privilegiados tienen a su disposición, siempre y cuando, como hemos advertido, dispongan de un título ejecutivo, el proceso de ejecución ordinario, regulado en la LEC con carácter general, aunque con las especialidades establecidas respecto a la venta forzosa del buque, tanto en el CPH 93 como en los artículos 480 ss LNM.

Ahora bien, puede ocurrir que, una vez iniciado éste, se conozca la existencia de otros acreedores titulares también de un crédito marítimo privilegiado, del que tenga que responder el mismo deudor y buque. Nos encontramos en este caso, con la necesidad de analizar dicho crédito y determinar, según el orden de prelación de estos créditos, el orden de cobro que le corresponde.

Pero, además, puede darse también el caso de que un acreedor titular de una hipoteca naval, ejercite, respecto de dicho buque, la acción ejecutiva que ésta le otorga, e inicie el proceso de ejecución hipotecario, también establecido en la LEC, como proceso ejecutivo, pero respecto del cual se aplican ciertas especialidades. También en este caso, habrá entonces que determinar si efectivamente existe dicho crédito, si es privilegiado y el lugar que ocupa en el orden de cobro respecto a los créditos hipotecarios o privilegiados.

Por todo lo expuesto, podemos afirmar que la cuestión más importante a tratar respecto de los privilegios marítimos la constituye, sin duda, la ejecución de los mismos, puesto que, como ya dijimos en su momento, estos privilegiados nacen con el objetivo de tratar de garantizar el cobro de los créditos a los que acompañan, quebrantando, para ello, el principio clásico par conditio creditorum, estableciendo la reipersecutoriedad de los mismos y evitando que entre en juego el derecho de retención de otros acreedores, si se diera el caso.

Así, dentro de este epígrafe, vamos a hacer referencia, en primer lugar, a las especialidades contempladas en el CPH 93 y en la LNM, respecto a venta forzosa del buque. Y, segundo lugar, nos centraremos en analizar la posibilidad de que, iniciado un proceso ejecutivo por un acreedor, ya sea éste privilegiado o no, comparezca otro acreedor titular de un crédito marítimo privilegiado y solicite que se tenga en cuenta el privilegio de su crédito y el cobro preferente con lo obtenido en la venta forzosa del buque.

\subsection{A La venta forzosa del buque}

A tenor de los establecido en el artículo 480 LNM, la venta forzosa del buque se realizará según lo establecido en la LEC para la subasta de bienes muebles sujetos a 
publicidad registral. Esta remisión a la LEC, no obstante, se ve matizada con algunas especialidades estipuladas en los artículos siguientes ${ }^{23}$.

En cuanto al régimen de notificaciones, establece el artículo 481 LNM, a continuación, un régimen especial, que deberá cumplirse de forma previa a que se produzca la venta forzosa del buque ${ }^{24}$. Así, podemos afirmar que antes de proceder a la venta forzosa del buque, la autoridad judicial o administrativa competente debe notificar dicha venta:

a) Al registrador titular del Registro de Bienes Muebles, así como a la autoridad competente encargada de la inscripción del buque en el Estado que lo hubiera autorizado a enarbolar temporalmente su pabellón, si fuere el caso.

b) A la persona que tenga inscrita a su favor la propiedad del buque.

c) A todos los titulares de las hipotecas o gravámenes inscritos que no hayan sido constituidos al portador.

d) A todos los titulares de las hipotecas o gravámenes inscritos constituidos al portador y de los privilegios marítimos internacionales reconocidos en el artículo $4 \mathrm{CPH} 93$, y la hipoteca naval, siempre que el juez u órgano administrativo competente hubiera recibido notificación de sus respectivos créditos.

Esta notificación debe realizarse con, al menos, treinta días de antelación a la fecha prevista para la venta forzosa y contendrá la fecha y el lugar de la venta, así como como toda la información relativa a ella o al proceso a través del cual se esté llevando a cabo, y que pueda ser necesaria para proteger los intereses de estas personas. Si no se conociese a tiempo el lugar y fecha, se realizará la notificación con fecha y lugar provisional, y cuando se tenga certeza, se comunicará esta información de nuevo.

Respecto al modo de realizar la notificación, se remite al sistema contemplado en la LEC y a la normativa administrativa correspondiente, según se trate de una venta judicial o administrativa, respectivamente, pudiendo realizarse por correo certificado, por medios electrónicos o por cualquier otro medio idóneo que permita obtener constancia de su recepción, aun cuando la persona a notificar tenga su domicilio fuera de España. No obstante, en caso de resultar aplicable un tratado internacional que así lo exija, la notificación se practicará por anuncios publicados en dos periódicos de ámbito nacional, pudiendo, además, insertarse los edictos en otras publicaciones si la autoridad judicial o administrativa que proceda a la venta forzosa lo estima conveniente.

Por otra parte, permite también el artículo 485 LNM que la venta forzosa del buque se realice por persona o entidad especializada, para lo cual se remite también al régimen previsto en el artículo 641 LEC sin ninguna especialidad o limitación.

\footnotetext{
${ }^{23}$ Vid. SANJUÁN MUÑOZ, E., "Especialidades procesales en la nueva Ley de la Navegación Marítima”, en AA.VV., Comentarios a la Ley de la Navegación Marítima, Valencia, Tirant lo Blanch, 2016, págs.475 a 498 .

${ }^{24}$ Coincide en los sustancial, este régimen con lo dispuesto en el artículo 11 CPH 93.
} 
En cuanto a los efectos de la venta forzosa, establece el artículo 484 LNM que una vez producida ésta, quedarán sin efecto y se ordenará la cancelación de todas las hipotecas y gravámenes inscritos, salvo aquellos en los que el comprador se hubiere subrogado con el consentimiento de los acreedores, así como todos los privilegios y otras cargas de cualquier género que pudieran recaer sobre el buque ${ }^{25}$.

Eso sí, en este caso, no resulta aplicable, por indicación expresa, ni el artículo 666 LEC sobre sobre la valoración de muebles para la subasta, ni el 668.3 LEC acerca de la consulta de la certificación e información registral del bien, ni el 670 LEC, sobre la aprobación del remate, el pago y la adjudicación de bienes al acreedor. El motivo de esta exclusión es que, si aplicásemos estos artículos, se produciría, en la práctica, una alteración en el orden de preferencia, con la consecuente pérdida de protección procesal para los acreedores titulares de un crédito marítimo privilegiado ${ }^{26}$.

\subsection{B Destino de la suma obtenida con la venta forzosa del buque}

El artículo 486 LNM, establece que no será de aplicación, a pesar de la remisión prevista a la LEC, el artículo 672 de la misma, en cuanto a al destino de las sumas obtenidas en la subasta. Ello se debe a que el propio CPH 93 y la LNM contemplan un régimen específico de pago y destino de las sumas obtenidas con la venta forzosa del buque.

Así, establece el artículo 486 LNM, en reflejo a lo establecido en el 12.2 CPH 93, que en el momento en que se produzca la venta del buque, se pagarán, en primer lugar, las costas y gastos causados desde el momento en que se produce el embargo preventivo o en la ejecución y venta judicial del buque. Estas costas y gastos los constituyen: ${ }^{27}$

1. El costo de la conservación del buque.

2. La manutención de la tripulación.

3. Los créditos laborales frente a la tripulación

4. Los gastos de repatriación de la tripulación.

5. Las Cuotas de la seguridad social de los miembros de la tripulación pagaderas en su nombre.

Por otra parte, en virtud del apartado 3 de este artículo 12 del CPH 1993, los Estados parte pueden añadir, dentro de este concepto de costas y gastos procesales derivados del embargo preventivo y la ejecución del buque, los gastos de remoción cuando se realice la

\footnotetext{
${ }^{25}$ A este respecto, se pronuncia también el artículo 12 CPH 93, estableciendo dos condiciones: a) que en el momento de la venta el buque se encuentre dentro del ámbito de la jurisdicción de ese Estado; y b) que la venta se haya efectuado de conformidad con la legislación de ese Estado y con lo dispuesto en el artículo 11 del propio Convenio.

${ }^{26}$ Estos problemas tenían lugar antes de que se modificase el régimen de venta forzosa del buque en la LNM. Para un análisis en profundidad de estas cuestiones, vid. CLAVERO TERNERO, M., “¿Afecta la Ley de Enjuiciamiento Civil 1/2000 a las preferencias entre privilegios marítimos e hipoteca naval?”, en Anuario de Derecho Marítimo, n²3, 2006, pág. 81 a 92.

${ }^{27}$ En idénticos términos se pronuncia el artículo 486 LNM, que reconoce la misma prioridad de pago por delante de cualquier tipo de crédito, a las costas y gastos procesales, e incluye los mismos conceptos que el CPH 1993.
} 
venta forzosa de un buque varado o hundido tras su remoción por una autoridad pública en interés de la seguridad de la navegación o de la protección del medio ambiente marino. Esta posibilidad ha sido recogida en el ordenamiento español a través del artículo 122.2 LNM.

En cualquier caso, lo importante es tener en cuenta que hasta que no se hayan satisfecho, en primer lugar, estas costas y gastos causados por el embargo preventivo y la ejecución del buque, no empieza realmente a asignarse el remanente al pago a los créditos del deudor marítimo.

\subsection{Los créditos marítimos privilegiados en los procesos ejecutivos iniciados por un tercero}

Decíamos anteriormente que, iniciado un proceso ejecutivo por un acreedor, ya sea este privilegiado o no, podía comparecer otro acreedor titular de un crédito marítimo privilegiado y solicitar que se tenga en cuenta el privilegio de su crédito y el cobro preferente con lo obtenido en la venta forzosa del buque.

Nos encontramos, entonces, con la necesidad de determinar cuál es el orden definitivo de prelación de créditos a tener en cuenta en estos casos, y el procedimiento a través del cual puede dicho acreedor hacer valer su privilegio en estos procesos ejecutivos.

\subsection{A Orden de prelación de créditos en la ejecución del buque}

Como ya vimos en el punto anterior, una vez realizada la venta del buque, se pagarán, en primer lugar, las costas procesales y gastos originados por el embargo preventivo o por la ejecución y subsiguiente venta del buque, y tras éstos, los créditos marítimos privilegiados reconocidos en el CPH 93.

Ahora bien, se nos plantea ahora la cuestión de cómo ordenar internamente, la prevalencia de créditos entre ellos, en aquellos casos en los que concurran diversos acreedores con privilegios marítimos. A ésta responde el apartado 2 del artículo 5 CPH 93, según el cual, el orden de prevalencia entre los privilegios marítimos es el siguiente:

1. ${ }^{\circ}$ Los créditos laborales debidos al capitán, los oficiales y demás miembros de la dotación del buque en virtud de su enrolamiento a bordo del buque, los gastos de repatriación y las cuotas de la seguridad social pagaderas en su nombre.

$2 .^{\circ}$ Los créditos por causa de muerte o lesiones corporales sobrevenidas, en tierra o en el agua, en relación directa con la explotación del buque, ya sean de naturaleza contractual o extracontractual.

$3 .^{\circ}$ Los créditos por salvamento marítimo del buque.

4. ${ }^{\circ}$ Los créditos por derechos derivados de los servicios recibidos por el buque durante su estancia en un puerto, canal y de otras vías navegables, así como de las ayudas recibidas a la navegación por contrato de practicaje. 
5. ${ }^{\circ}$ Los créditos nacidos de la culpa extracontractual por razón de la pérdida o daños materiales causados por la explotación del buque.

Eso sí, se establece también una regla especial respecto a los créditos por salvamento marítimo del buque, pues éstos tendrán preferencia sobre todos los demás privilegios marítimos que ya existieran antes de realizarse las operaciones de salvamento. Quiere esto decir, entonces, que los créditos por salvamento marítimo del buque, adelantan a los créditos laborales y a los créditos por daños anteriores a las operaciones de salvamento, pero mantienen su posición respecto a los nacidos con posterioridad.

El motivo por el que se dispensa un trato tan distinto a los privilegios marítimos nacidos de los créditos por salvamento marítimo, es doble. De un lado, porque gracias a las operaciones de salvamento realizadas, el buque o aeronave objeto de garantía, está disponible para la venta judicial, y, por tanto, que gracias al auxilio prestado puedan cobrar su crédito los demás acreedores, privilegiados o no. Y, de otro lado, además, porque se pretende con ello incentivar a los operadores del salvamento para que lleven a cabo esta labor.

Pero, además, debemos prever que pueden concurrir diversos créditos marítimos privilegiados que ocupen el mismo orden de prelación, en cuyo caso, concurrirán entre ellos a prorrata, salvo que se trate de créditos por salvamento marítimo, en cuyo caso, en aplicación de la regla especial que acabamos de ver, tendrán prelación entre sí por el orden inverso al de la fecha de nacimiento de los créditos garantizados con esos privilegios, en virtud de la fecha en que concluyó cada operación de salvamento.

Satisfechos los privilegios marítimos, es momento de referirnos a los derechos retención de los constructores o reparadores de buques. Dijimos con anterioridad que uno de los efectos que se derivan de los privilegios marítimos, es que impedía la aplicación del derecho de retención de estos acreedores. Esto es así porque el artículo 12.4 CPH 93, establece que, en caso de existir un derecho de retención reconocido a favor de un constructor o reparador de buques, por la legislación nacional del Estado parte en que se realiza la venta judicial del buque, el constructor o reparador de buques deberá entregar al comprador la posesión del buque, pero podrá obtener el pago de su crédito una vez satisfechos los créditos de los titulares de los privilegios marítimos de origen internacional ${ }^{28}$.

Como puede observarse, estos acreedores pierden la posibilidad de ejercitar su derecho de retención para facilitar la venta judicial del buque, pero, a cambio, obtienen la ventaja de posicionar su crédito justamente tras el pago de los privilegios marítimos internacionales, quedando, incluso por delante, del pago de la hipoteca naval, y otras cargas y gravámenes inscritos, así como de los privilegios marítimos de origen nacional propios de cada Estado. Ahora bien, recordamos también en este momento que, en lo que se refiere a la legislación española, el artículo 139 LNM limita esta ventaja al constructor

${ }^{28}$ Acerca del régimen de estos privilegios vid. MARTÍNEZ DE AZCOITIA, L. Y SÁNCHEZ-FAYOS MARTÍN-PEÑA, J., "La hipoteca naval en el ordenamiento jurídico español tras la entrada en vigor de la Ley 14/2014 de navegación marítima", Revista de Derecho del Transporte, nº 19, 2017, pág. 163. 
cuando en virtud de pacto la propiedad del buque pertenezca al comitente, lo cual supone que el comitente debe ser el propietario del buque.

Ahora sí, tras el pago de los créditos que acabamos de examinar, corresponde satisfacer las hipotecas, cargas o gravámenes, siempre que cumplan con los siguientes requisitos de establecidos en el CPH 93:

1. Que hayan sido constituidos e inscritos en un registro de conformidad con la legislación del Estado en que esté matriculado el buque.

2. Que el registro y los documentos que se hayan de presentar al registrador, puedan ser libremente consultados por el público y se pueda solicitar al registrador el libramiento de extractos del registro y copias de esos documentos.

3. Que en el registro o en alguno de estos documentos presentados al registrador y consultables por el público, se especifique, por lo menos, el nombre y la dirección de la persona a favor de la cual se haya constituido la hipoteca, el mortgage o el gravamen, o el hecho de que esa garantía ha sido constituida al portador; el importe máximo garantizado, si la legislación del Estado de matrícula estableciere ese requisito o si ese importe se especificare en el documento de constitución de la hipoteca, el mortgage o el gravamen; y la fecha y otras circunstancias que, de conformidad con la legislación del Estado de matrícula, determinen su rango respecto de otras hipotecas, mortgages y gravámenes inscritos.

Una cuestión que debemos tener en cuenta al hablar de las hipotecas, cargas y gravámenes inscritos, es la de los derechos refaccionarios. El CPH 93 no hace referencia expresa a ellos, pero el artículo 138 LNM sí que los recoge como categoría de créditos, entendidos como aquellos créditos que tienen como objetivo financiar la construcción o reparación del buque o aeronave ${ }^{29}$. Actualmente, estos créditos se sitúan al mismo nivel de los créditos hipotecarios, es decir, como auténticos créditos privilegiados con derecho real de garantía, pues así lo establece el artículo 138 LNM, siempre que tales créditos figuren inscritos o anotados en el Registro de Bienes Muebles, rigiéndose esta anotación por lo dispuesto en la legislación hipotecaria aplicable a los buques ${ }^{30}$. Es más, dispone, a continuación, este artículo que la anotación surtirá todos los efectos de la hipoteca sin necesidad de convertirse en inscripción y tendrá la duración de cuatro años y las prórrogas establecidas con carácter general para las anotaciones preventivas.

Por tanto, puede decirse que los créditos refaccionarios, serán considerados créditos privilegiados con derecho real de garantía, en caso de que estén debidamente inscritos o anotados en el Registro, por el contra, aquellos créditos refaccionarios no inscritos o anotados, no disponen de derecho real de garantía, por lo que quedan en la categoría de créditos con privilegio especial, y solamente, como decíamos al principio, podrán situarse con preferencia en el cobro, por delante de los acreedores ordinarios.

\footnotetext{
${ }^{29}$ Para un estudio en profundidad del nacimiento y evolución de estos créditos desde la antigua Roma hasta el Derecho Marítimo moderno, vid. GABALDÓN GARCÍA, J.L., Los privilegios marítimos sobre el buque, op. cit., pp. 23 a 25.

${ }^{30}$ En la Ley Hipotecaria, los créditos refaccionarios se regulan en los artículos 59 a 64.
} 
Llega, por último, el turno de los privilegios marítimos de ámbito nacional creados en virtud del artículo $6 \mathrm{CPH}$ 93, pues éstos no se encuentran incluidos en el orden de ejecución que hemos analizado para los privilegios marítimos internacionales reconocidos en el CPH 93, sino que ocupan el último puesto en el orden de pago, tras los privilegios reconocidos en el Convenio, y, lo que, es más, se sitúan tras el pago a hipotecas, cargas o gravámenes que cumplan con los requisitos mínimos de inscripción y publicidad registral.

Por tanto, podemos finalmente decir que el orden por el que se deben satisfacer los créditos, en caso de ejecución del buque o aeronave es el siguiente:

1. Costas procesales y gastos originados por el embargo preventivo o por la ejecución y subsiguiente venta del buque.

2. Los créditos por salvamento marítimo del buque

3. Los privilegios marítimos de origen internacional reconocidos en el $\mathrm{CPH} 93$ :

a. Los créditos laborales debidos al capitán, los oficiales y demás miembros de la dotación del buque en virtud de su enrolamiento a bordo del buque, los gastos de repatriación y las cuotas de la seguridad social pagaderas en su nombre.

b. Los créditos por causa de muerte o lesiones corporales sobrevenidas, en tierra o en el agua, en relación directa con la explotación del buque, ya sean de naturaleza contractual o extracontractual.

c. Los créditos por salvamento marítimo del buque.

d. Los créditos por derechos derivados de los servicios recibidos por el buque durante su estancia en un puerto, canal y de otras vías navegables, así como de las ayudas recibidas a la navegación por contrato de practicaje.

e. Los créditos nacidos de la culpa extracontractual por razón de la pérdida o daños materiales causados por la explotación del buque.

4. Los créditos por construcción o reparación del buque que diesen origen a un derecho de retención a favor de sus acreedores.

5. Hipoteca naval, cargas y gravámenes, y derechos refaccionarios correctamente constituidos e inscritos.

6. Privilegios marítimos nacionales propios de cada estado y creados al amparo del CPH 93.

7. Créditos con privilegio especial

8. Créditos con privilegio general

9. Créditos ordinarios.

\subsection{B Las tercerías de mejor derecho}

1. Proceso ordinario de ejecución

Como es sabido, el proceso ordinario de ejecución es el proceso de ejecución general por excelencia a través del cual los titulares de cualquier tipo de crédito pueden tratar de ver satisfechos sus intereses, a través del embargo de los bienes del deudor. Ahora bien, el hecho de que un acreedor, con independencia de la naturaleza de su crédito, pueda iniciar este proceso de ejecución singular, no significa que no puedan tenerse en cuenta en el 
mismo otros créditos de otros acreedores, si no que, muy al contrario, los titulares de otros créditos distintos al que da inicio al proceso de ejecución pueden intervenir en éste, ejercitando la acción que corresponda según la naturaleza de su crédito y, en este caso, entonces, habrá de tenerse en cuenta el orden de prelación existente entre todos ellos.

La institución que permite la intervención de un acreedor en un proceso de ejecución ajeno iniciado por el titular de otro crédito distinto al suyo no es otra que la tercería de mejor derecho, regulada en la LEC, y a la cual remite la propia LNM en su artículo 483.1, cuando regula la venta forzosa de buques, al disponer expresamente que los titulares de créditos marítimos privilegiados podrán comparecer y formular la correspondiente tercería de mejor derecho, en la forma y con los efectos previstos en los artículos 614 a 620 LEC.

Por tanto, la tercería de mejor derecho permite así que, iniciado un proceso de ejecución, un tercero distinto al ejecutante y ajeno al mismo, ejercite una o varias acciones entrando en el proceso y haciendo valer su privilegio y preferencia en el cobro del crédito del que es titular, de manera que, sin impedir que dicho proceso continúe, vería su crédito satisfecho en primer lugar, y con prioridad al crédito del ejecutante, con la suma obtenida tras la enajenación forzosa del bien.

Las acciones a ejercitar dependerán, no obstante, de si el tercerista dispone o no de título ejecutivo donde conste su crédito, pues, si es así, bastará con dirigir su demanda frente al ejecutante, pero, en caso contrario, ésta deberá ir frente a ejecutante y ejecutado, ya que, no sólo debe, en este caso, acreditar y probar el privilegio de su crédito y la preferencia en el cobro frente al crédito del ejecutante, sino también, la existencia en sí misma del propio crédito, tal y como tuvimos ocasión de ver al analizar ${ }^{31}$.

Otra cuestión importante a tener en cuenta en este sentido, es la determinación del momento a partir del cual que puede, el titular del crédito marítimo privilegiado, hacer valer su preferencia de cobro solicitando incorporarse al proceso de ejecución ya iniciado, pues no debemos olvidar que se trata de un privilegio especial, es decir, que la preferencia en el cobro de estos créditos está directamente relacionada con el embargo y la venta judicial del buque o aeronave.

Siendo así, conviene señalar, que el momento inicial a tener en cuenta en este caso, no es desde que se acuerda el despacho de la ejecución, como ocurre con los privilegios generales, si no, desde el momento en que se produce el embargo del buque, y hasta que se haga entrega al ejecutante de la suma adeudada para saldar su crédito obtenida mediante la ejecución forzosa de la aeronave.

No obstante, no debemos confundir el momento a partir del cual puede el titular del privilegio marítimo solicitar entrar en el proceso de ejecución interponiendo la correspondiente demanda de tercería, con el momento a partir del cual se hará efectiva dicha entrada, pues esta circunstancia depende, no del tipo de privilegio, si no de si dicho crédito privilegiado consta o no en un título ejecutivo, de manera que, en caso de disponer

\footnotetext{
${ }^{31}$ Así se desprende del artículo 617.2 LEC.
} 
de dicho título, si que podrá intervenir en la ejecución desde que resulte admitida la demanda, pero si no dispone de éste, sólo podrá intervenir en el proceso cuando se estime su demanda, en caso, por supuesto, de que esto tenga lugar finalmente.

Eso sí, en caso de estimarse la tercería, antes de entregar al acreedor del privilegio marítimo la cantidad estipulada, habrá de satisfacerse al ejecutante las tres quintas partes de las costas causadas hasta el momento en que se hubiese dictado la sentencia de tercería.

2. Proceso de ejecución hipotecario

Además de poder acudir al proceso ordinario de ejecución, determinados acreedores en determinadas circunstancias, como ya hemos visto, tienen también la posibilidad de reclamar la satisfacción de su crédito a través del conocido proceso hipotecario, el cual presenta determinadas especialidades en relación al primero, con las que se intenta beneficiar la posición de los titulares de estos créditos específicos.

Así, este proceso especial, puede ser utilizado para exigir el pago de deudas garantizadas por prenda o hipoteca directamente contra los bienes pignorados o hipotecados, lo que incluye expresamente a las deudas garantizadas por hipoteca naval, siempre y cuando, el ejercicio de esta acción se deba a alguna de las causas, previstas en los apartados a) y e) del artículo 140 LNM, esto es, o que se haya producido el vencimiento del plazo para la devolución del capital o para el pago de los intereses, en la forma que se hubiere pactado, o que se cumplan las condiciones pactadas como resolutorias de la obligación garantizada, y todas las que produzcan el efecto de hacer exigible el capital o los intereses ${ }^{32}$.

En caso de darse otras circunstancias distintas a éstas, pero reconocidas también en los restantes apartados del artículo 140 LNM, para poder ejercitar esta acción será necesario, si es por la declaración en concurso del deudor, presentar testimonio de la ejecutoria donde conste la declaración de concurso; y si es porque el buque hipotecado sufre un deterioro que lo inutilice definitivamente para navegar o si existieren dos o más buques afectos al cumplimiento de una misma obligación y ocurriese la pérdida o deterioro que inutilice definitivamente para navegar a cualquiera de ellos, salvo pacto en contrario, presentar certificación emitida por la Administración competente donde constate la situación real del buque ${ }^{33}$.

Llegados a este punto, podemos preguntarnos por la relación entre este proceso especial de ejecución con los créditos marítimos privilegiados, pues a pesar de ser considerados éstos, derechos de garantía sobre el buque de origen legal, llegando incluso a ser

\footnotetext{
${ }^{32}$ En caso de darse la circunstancia prevista en el apartado a) del artículo 140 LNM, debe tenerse en cuenta, además, lo establecido en el artículo 693 LEC, según el cual, para poder hacer uso de este proceso, debe haberse dejado de pagar una parte del capital del crédito o los intereses, cuyo pago deba hacerse en plazos, si vencieren al menos tres plazos mensuales sin cumplir el deudor su obligación de pago o un número de cuotas tal que suponga que el deudor ha incumplido su obligación por un plazo al menos equivalente a tres meses.

${ }^{33}$ Debe tenerse en cuenta, no obstante, que además de esta exigencia específicamente relacionada con la hipoteca naval, e introducida en la LEC a través de la LNM de 2014, deben cumplirse, también, una serie de requisitos establecidos de forma general en la regulación que hace de este proceso la LEC en sus artículos 681 ss.
} 
calificados como hipotecas legales tácitas, ya vimos que no cumplen los requisitos para poder acudir a este procedimiento. Sin embargo, no podemos olvidar que como hemos visto a lo largo de este estudio, los créditos con privilegios marítimos se sitúan, en el orden de prelación de créditos, por encima de la hipoteca naval, de manera que, es necesario tener en cuenta, en este procedimiento también, la institución de la tercería de mejor derecho, dado que, así lo autoriza expresamente el artículo 483.2 LNM, según el cual, los titulares de créditos marítimos privilegiados podrán comparecer y formular las correspondientes tercerías de mejor derecho en cualquier procedimiento judicial de ejecución de hipoteca naval.

Eso sí, debe tenerse en cuenta que los privilegios marítimos de ámbito nacional creados en virtud del artículo $6 \mathrm{CPH} \mathrm{93,} \mathrm{como} \mathrm{ya} \mathrm{dijimos} \mathrm{en} \mathrm{su} \mathrm{momento,} \mathrm{no} \mathrm{se} \mathrm{encuentran}$ incluidos en el orden de ejecución que hemos analizado para los privilegios marítimos internacionales reconocidos en el CPH 93, sino que ocupan el último puesto en el orden de pago, tras los privilegios reconocidos en el Convenio, situándose, incluso, tras el pago de hipotecas, cargas o gravámenes que cumplan con los requisitos mínimos de inscripción y publicidad registral.

\section{CONCLUSIONES}

A lo largo de estas páginas, hemos podido comprobar que no son pocas las cuestiones controvertidas que se plantean respecto a los créditos marítimos privilegiados. Se entrelazan en esta figura instituciones y principios presentes en los ordenamientos jurídicos de las civilizaciones actuales desde tiempos remotos pues, como es de sobra conocido, la navegación marítima es, y ha sido siempre, un pilar básico en el desarrollo de la vida humana.

Además, debemos tener presente una confluencia de distintas ramas del Derecho, pues se trata de una materia profundamente interdisciplinar. De un lado, nos encontramos frente al Derecho Marítimo en estado puro. Pero también, frente al Derecho Mercantil, pues no cabe duda alguna de que una parte fundamental del Derecho Marítimo, está conformada por el comercio marítimo. Y, de igual manera, están relacionados con el Derecho Civil, y particularmente con el Derecho Crediticio; el Derecho Administrativo, el Derecho Laboral, y como no podía ser de otra manera, con el Derecho Procesal. Y todo ello, marcado con un profundo carácter internacional, ya que la internacionalidad es consustancial al propio Derecho de la Navegación Marítima.

Por todo ello, como ya advertimos al inicio de estas páginas, la existencia de los créditos marítimos privilegiados no da lugar, únicamente, a un criterio de ordenación de créditos y acreedores si no que éstos remiten a un conjunto de numerosas especialidades a tener en cuenta, tanto respecto de su configuración legal y regulación sustantiva, como respecto de la perspectiva procesal.

En primer lugar, debe tenerse en cuenta la existencia tanto de créditos marítimos privilegiados de carácter y origen internacional, es decir, los reconocidos en el CPH 93, 
como de origen nacional, propios de cada Estado, ya que alcance y régimen del privilegio es distinto en cada caso.

Por otra parte, también es importante destacar que estos privilegios poseen una naturaleza jurídica accesoria, es decir, que acompañan al crédito, pero tienen identidad e independencia respecto al mismo, de manera que existen causas de extinción del crédito y causas propias de extinción del privilegio, pudiendo darse la situación de estar extinguido el privilegio, pero no el crédito. A este respecto, nos encontramos con una cuestión de gran importancia: la posibilidad de suspender o interrumpir el plazo de prescripción establecido para reclamar el crédito reconociendo los efectos del privilegio. A nuestro entender, sería posible entenderlo así, en caso de que no se pueda proceder al embargo preventivo o a la ejecución del buque, eso sí, por imperativo legal.

También en lo concerniente al reconocimiento y ejecución del privilegio, encontramos que la regulación no es taxativamente clara sobre las acciones ejercitables en relación a estos créditos y los procesos a través de las que éstas se pueden ejercitar. Esto se debe a la evolución que se ha ido produciendo a lo largo de los años en la regulación sustantiva, fundamentalmente en lo que al régimen internacional se refiere, pues los propios créditos con privilegios marítimos pasan de ser créditos formalmente constituidos y publicitados, a créditos informales con mínimos requisitos de constitución y publicidad. Por tanto, el tratamiento procesal que se dispense no se puede pretender que sea el mismo.

Así, si bien es cierto que, tradicionalmente se ha venido afirmando que uno de los efectos principales de estos créditos es que son directamente ejecutables, en la actualidad, y con la regulación que de los mismos encontramos en el CPH 93 y en nuestra propia legislación nacional, esta afirmación ya no resulta cierta, con carácter general, si no que, por el contrario, para poder tramitarse un proceso de ejecución, será necesario, en la mayor parte de los casos, obtener un título ejecutivo que lo permita a través del correspondiente proceso declarativo.

Y no es esta una cuestión simple ni carente de importancia, si no todo lo contrario, fundamental para poder obtener la tan necesaria tutela judicial efectiva y protección del crédito.

Por tanto, hemos podido ver, ahora ya, al término de este estudio, como, efectivamente, son muchas las especialidades que presentan en ambos sentidos, pero, si bien, suele ponerse el acento o recalcarse la importancia de los efectos que estos créditos producen en el Derecho de la Navegación Marítima y en el Derecho Crediticio, nosotros hemos querido hacer hincapié en una serie de cuestiones procesales, igualmente importantes, que deben también tenerse en cuenta a la hora de hacer valer el privilegio con que cuentan estos créditos; cuestiones que, desde hace no pocos años, han supuesto auténticos problemas en la materialización de ese conocido derecho de realización derivado de los créditos con privilegio marítimo.

A nuestro entender, los textos legales que regulan estos créditos, tanto el $\mathrm{CPH} 93$, como la LNM, han sabido, con su evolución legislativa y modernización, ir resolviendo muchos de estos problemas, aunque, no obstante, sería conveniente realizar una mejora 
sistemática y conceptual de lo que podríamos denominar el Derecho Procesal Marítimo, pues pondría fin a las cuestiones que aún hoy siguen en debate y simplificaría la tutela procesal que reciben estos acreedores.

\section{BIBLIOGRAFÍA}

ALONSO LEDESMA, C., "Viejos y nuevos problemas de los privilegios marítimos", en AA.VV., Estudios de Derecho Marítimo, Navarra, Cizur Menor (Thomoson Reuters Aranzadi), 2012, pág. 293 a 316.

CASAS ROBLA, J., "Los privilegios marítimos", en AAVV., Comentarios a la Ley de la Navegación Marítima, Madrid, Dykinson, 2015, pág.91 a 108.

CLAVERO TERNERO, M., “¿Afecta la Ley de Enjuiciamiento Civil 1/2000 a las preferencias entre privilegios marítimos e hipoteca naval?", en Anuario de Derecho Marítimo, n²3, 2006, pág. 81 a 92.

DEL CORTE LÓPEZ, J., Especialidades procesales en la Ley de la navegación marítima, en AA.VV. Comentarios sobre la ley de la navegación marítima, Madrid, Marcial Pons, 2015, pág. 753 a 780.

DÍEZ SOTO, C.M., "Los privilegios crediticios como mecanismo de protección del crédito", en AA.VV., Preferencias de créditos, Manuales de formación continuada 2, Consejo General del Poder Judicial, Madrid, 2000, pág. 23 a 155.

DOMÍNGUEZ CABRERA, M.P., "La ejecución extraconcursal del buque”, Anuario de Derecho Marítimo, núm. 27, 2010, pág. 117 a 174.

FONTESTAD PORTALÉS, L., Conocimiento de embarque como título ejecutivo, Tirant Lo Blanch, Valencia, 2007.

FONTESTAD PORTALÉS, L., Navegando hacia el futuro: propuestas de reformas procesales en la LNM y el impacto de la inteligencia artificial en el transporte marítimo, Navarra, Aranzadi, 2021.

GABALDÓN GARCÍA, J.L., Los privilegios marítimos sobre el buque, tesis doctoral presentada en Madrid en 1992.

GABALDÓN GARCÍA, J.L. Y RUÍZ SOROA, J.M., Manual de Derecho de la Navegación, Marítima, Madrid, Marcial Pons, 2006.

MARTÍNEZ DE AZCOITIA, L. Y SÁNCHEZ-FAYOS MARTÍN-PEÑA, J., "La hipoteca naval en el ordenamiento jurídico español tras la entrada en vigor de la Ley 14/2014 de navegación marítima", Revista de Derecho del Transporte, nº 19, 2017, pag. 143 a 163 . 
PULIDO BEGINES, J.L., Instituciones de Derecho de la Navegación Marítima, Madrid, Tecnos, 2009,

ROBLES GARZÓN, J.A., "La función jurisdiccional”, en AA.VV., Conceptos de Derecho Procesal Civil, Madrid, Tecnos, 1ªed., 2017, pág. 51 a 61

RUEDA MARTÍNEZ, J.A., Los privilegios marítimos, en AA.VV. Comentarios sobre la Ley de la Navegación Marítima, Madrid, Marcial Pons, 2015, pág. 173 a 196.

RUEDA MARTÍNEZ, J.A., Los privilegios marítimos, en AA.VV. Ley de la Navegación Marítima, balance de su aplicación práctica. Madrid, Marcial Pons, 2019, pág. 121 a 142

RUIZ SOROA, J.M., "Los privilegios marítimos", en AA.VV.. Preferencias de créditos, Manuales de formación continuada 2, Consejo General del Poder Judicial, Madrid, 2000, pp. 311 a 369.

SANJUÁN MUÑOZ, E., "Especialidades procesales en la nueva Ley de la Navegación Marítima", en AA.VV., Comentarios a la Ley de la Navegación Marítima, Valencia, Tirant lo Blanch, 2016, 128urop.475 a 498.

VEIGA COPO, A.B., "Privilegios sobre buques y aeronaves", en AA.VV., Enciclopedia de Derecho Concursal, t.II, Navarra, Cizur menor (Aranzadi), 2012, pág. 2357 a 2366.

VELASCO NATES, A., "El derecho de retención de la mercancía como garantía del pago del flete, demoras y otros gastos en la Ley de la Navegación Marítima", en AA.VV., Comentarios a la Ley de la Navegación Marítima, Madrid, Dykinson, 2015, pp. 197 a 210. 